\title{
Masson's Tumor Masquerading as a Papillary Adenocarcinoma on Fine Needle Aspiration Cytology: A Case Report
}

\author{
Anita NANGIA, Shivali SEHGAL, Kiran AGARWAL
}

Department of Pathology, Lady Hardinge Medical College, DELHI, INDIA

\begin{abstract}
Intravascular papillary endothelial hyperplasia, previously known as Masson's tumor, is a relatively uncommon reactive endothelial proliferation that occurs most commonly in the vessels of the head, neck, and extremities. We report a case of intravascular papillary endothelial hyperplasia in the neck in a 40-year-old female that was misdiagnosed as papillary adenocarcinoma on fine needle aspiration. The cytologic picture of intravascular papillary endothelial hyperplasia is diverse, making a pinpoint diagnosis of this entity difficult on fine needle aspiration.
\end{abstract}

Key Words: Masson's tumor, Papillary adenocarcinoma, Fine needle aspiration

\section{INTRODUCTION}

Intravascular papillary endothelial hyperplasia (IPEH), previously known as 'Masson's tumor, is a relatively uncommon reactive endothelial proliferation that occurs most commonly in the vessels of the head, neck, and extremities. It has slight predilection for women and has been reported in the age range of 9 months to 80 years (1). The cytologic findings of the lesion are varied. We report a case of IPEH in the neck that was initially misdiagnosed as a papillary adenocarcinoma on fine needle aspiration (FNA).

\section{CASE REPORT}

A 40-year-old female presented with a swelling in the neck that was noticed 2 years ago and was progressively increasing in size. It was a well defined, firm, mobile and non tender swelling measuring $1.5 \mathrm{x} 1 \mathrm{~cm}$ in the left upper cervical region. The overlying skin was unremarkable. On FNA, blood-mixed aspirate was obtained after which the swelling partly reduced in size.

Smears were haemorrhagic showing cells lying singly, in small nests, large clusters and in papillary fragments along with presence of vascular tissue fragments (Figure 1). Individual cells showed overlapping and were large with moderate to abundant amount of cytoplasm with many cells showing cytoplasmic vacuolisation. The nucleus was central to eccentric, round to oval with moderate degree of anisonucleosis, finely clumped chromatin and 1-2 prominent nucleoli (Figure 1, inset). There was a vague

(Turk Patoloji Derg 2018, 34:179-181)

Received : 31.03.2015 Accepted : 29.07.2015 attempt to form acinar or papillaroid structures (Figure 2). However, no intranuclear inclusions, psammoma bodies or peripheral pallisading were seen in the smears examined. Few mitotic figures were seen. The presence of pleomorphic cells arranged in papillaroid and glandular patterns was suspicious of metastatic papillary adenocarcinoma. The patient was advised urgent excision. The section showed numerous intravascular papillary structures along with thrombosis at some foci (Figures 3,4). The features were suggestive of IPEH. Immunohistochemistry was done and CD34 was found to be positive in the cells lining the papillae, confirming their endothelial origin. CD34 was also found to be positive in the adjacent fibrous stroma. A final diagnosis of IPEH was made.

\section{DISCUSSION}

IPEH is a benign neoplasm of endothelial cells that has been well described in the surgical pathology literature. This entity is now regarded as an exuberant form of organizing thrombus rather than a true neoplasm (2). It can involve an isolated dilated blood vessel or occur as a focal change in preexisting vascular lesions such as hemangiomas and varices, or rarely present in an extravascular location, in the setting of a hematoma (2).

IPEH may be confused with a malignancy based on FNA, particularly when the lesion occurs in uncommon anatomic locations. There are only a few published reports on aspiration cytology of IPEH. The markedly atypical

Correspondence: Shivali SEHGAL

Lady Hardinge Medical College, Department of Pathology, DELHI, INDIA

E-mail: shivalisehgal@gmail.com Phone: +981 8770874 


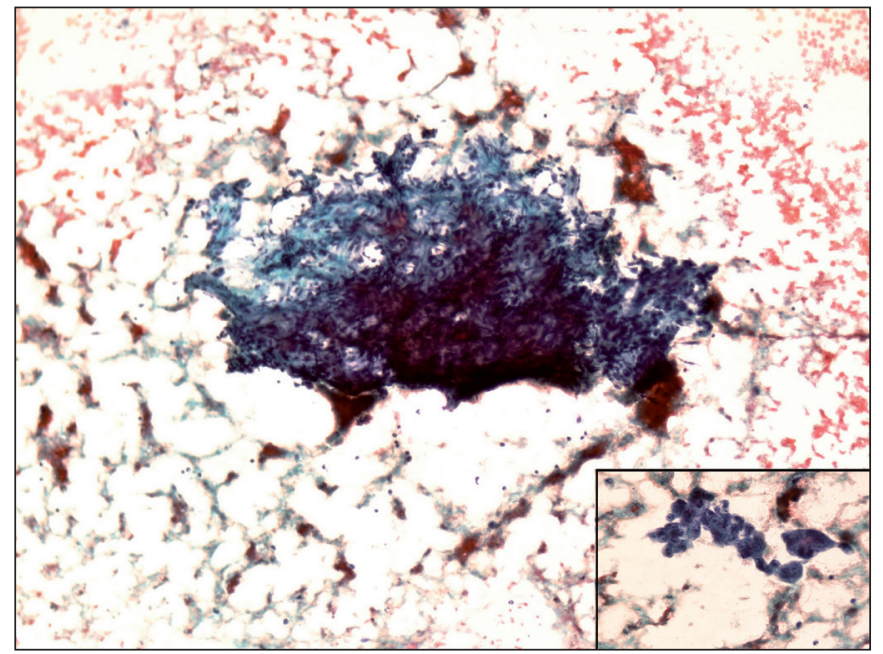

Figure 1: Photomicrograph showing branching papillary arrangement of cells (PAP; x100). Inset shows cells with nuclear atypia (PAP; x400).

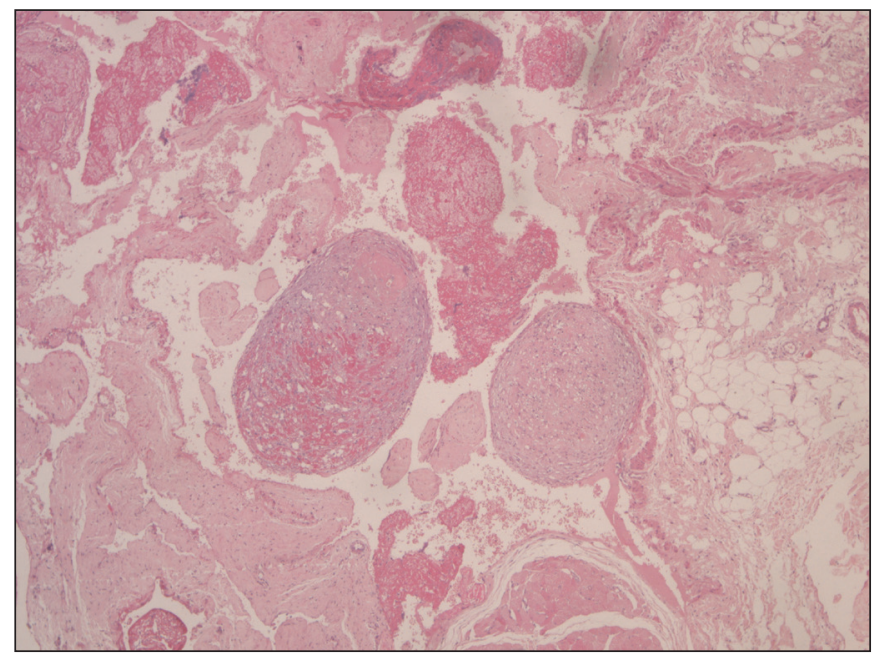

Figure 3: Photomicrograph showing numerous intravascular papillary structures with thrombosis at some foci (H\&E; x100).

appearance of aspirated endothelial cells, the absence of specific features and the lack of cell block material for morphological and immunohistochemical evaluation has resulted in misdiagnosis of IPEH as a malignant neoplasm on cytology aspirates in the past (3-8).

Vascular tissue fragments should be differentiated from granulomas and granulation tissue. Vascular fragments are composed of cords and strands of spindle-shaped cells (with blunt nuclei) representing capillary vessels separated by connective tissue and are often found on a background of profuse blood. Granulomas are cohesive clusters of epithelioid cells, lymphocytes, plasma cells and giant cells. Granulation tissue is composed of cohesive clusters of

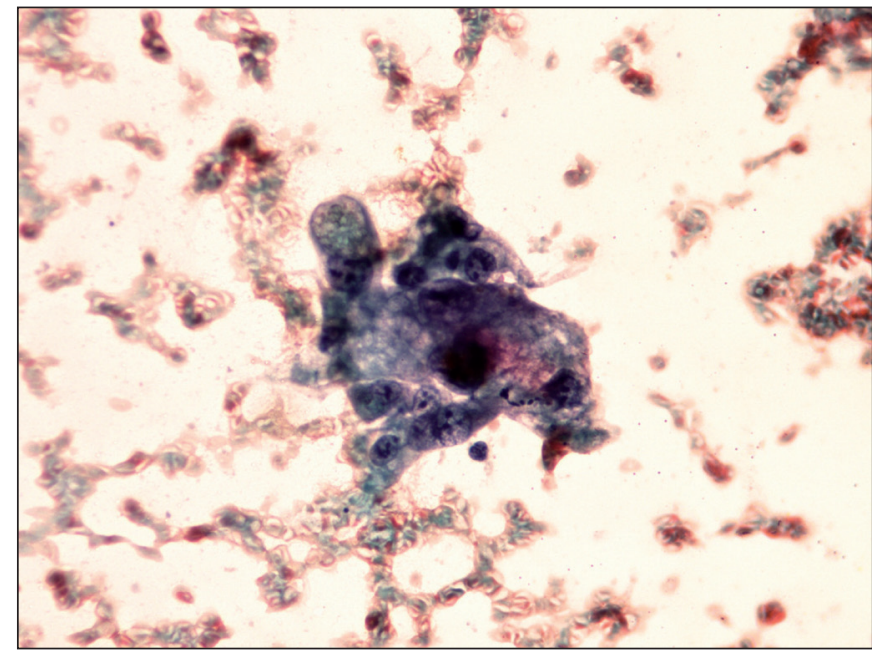

Figure 2: Photomicrograph showing cells arranged in vague acinar pattern. Note the nuclear atypia of cells and an occasional cell showing fine cytoplasmic vacuolisation (PAP; $x 400$ ).

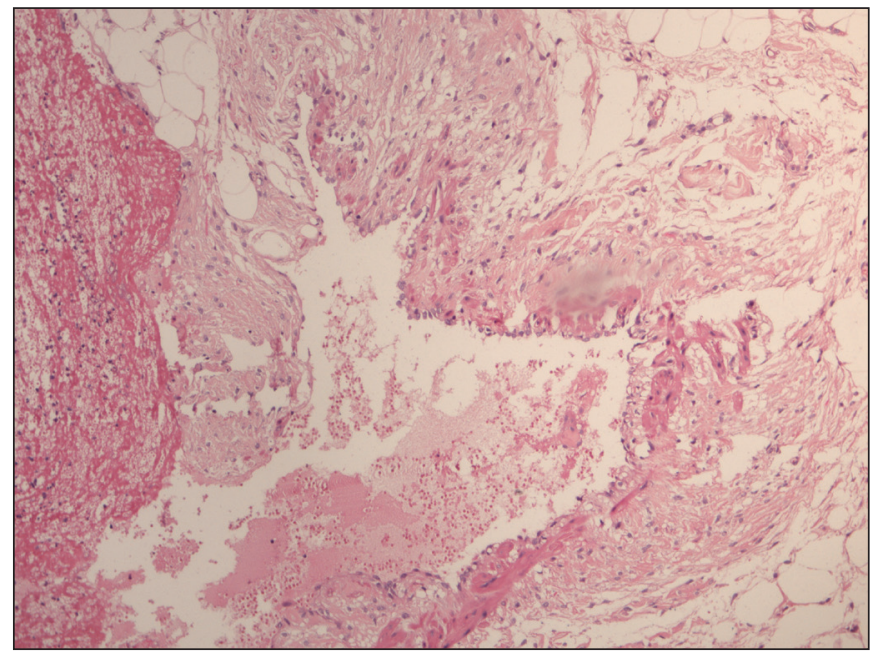

Figure 4: Photomicrograph showing vascular lumen lined by endothelial cells (H\&E; x100).

fibroblasts, histiocytes, inflammatory cells and capillary vessels.

The cytological picture of IPEH is varied and thus the differential diagnosis is challenging. The cases reported by Novak et al. and Karim et al. were diagnosed as squamous cell carcinomas on cytology due to the presence of dense cytoplasm, hard cell borders, pleomorphic nuclei and prominent, multiple nucleoli $(4,6)$. Suh et al. and Yoo-Duk $\mathrm{C}$ et al. noted pleomorphic polygonal cells arranged in alveolar or glandular clusters in the smears suggesting the diagnosis of adenocarcinoma $(5,9)$. However, the former case was diagnosed as metastatic embryonal carcinoma in view of the patient's young age. Jain et al. noted cords and 
globular forms of hyaline material surrounded by plump endothelial cells and interpreted them as diagnostic of adenoid cystic carcinoma (7). Garcia-Macias et al. reported two distinct populations of cells in IPEH (3). One type had large nuclei, finely granular chromatin, prominent nucleoli and abundant globular cytoplasm, with occasional single cytoplasmic vacuoles. The second type of cells had spindle to oval nuclei with granular chromatin and scanty eosinophilic cytoplasm. This group identified correctly the vascular nature of the cells, but considered it to be probably malignant due to cellular atypia. Handa et al. reported a IPEH on the wrist with presence of giant cells and spindle cells on FNA smears which they interpreted as a giant cell tumor (10).

In conclusion, the cytologic features of IPEH are not specific, which often result in diagnostic challenges. However, it is important to suspect a vascular lesion when atypical cells are found on a hemorrhagic background. Furthermore, combination of cytologic features with immunocytochemistry will aid in the correct diagnosis of IPEH.

\section{REFERENCES}

1. Clearkin KP, Enzinger FM. Intravascular papillary endothelial hyperplasia. Arch Pathol Lab Med. 1976;100:441-4.

2. Weiss SW, Goldblum JR. Papillary endothelial hyperplasia (vegetant intravascular hemangioendothelioma, intravascular angiomatosis) In: Weiss SW, Goldblum JR, editors. Enzinger and Weiss's soft tissue tumors. Mosby: St. Louis; 2008;668-71.
3. García-Macías MC, Abad M, Alonso MJ, Flores T, Bullón A. Masson's vegetant intravascular hemangioendothelioma: Fine needle aspiration cytology, histology and immunohistochemistry of a case. Acta Cytol. 1990;34:175-8.

4. Novak JA, Ferguson DJ, Komorowski RA. Fine needle aspiration cytology of papillary endothelial hyperplasia: A case report. Acta Cytol. 1999;43:663-6.

5. Suh KS, Shin KS, Park IA. Intravascular papillary endothelial hyperplasia of the neck masquerading as malignancy on fineneedle aspiration cytology. Diagn Cytopathol. 2003;29:14-7.

6. Karim RZ, Merani R, Shannon K, Watson G. Papillary endothelial hyperplasia of the orbit: Report of a case highlighting a pitfall on fine needle aspiration biopsy. Acta Cytol. 2007;51:207-10.

7. Jain S, Khurana N, Gulati A. Intravascular papillary endothelial hyperplasia of the palate masquerading as adenoid cystic carcinoma on fine needle aspiration cytology: A potential diagnostic pitfall. Cytopathology 2012;23:198-200.

8. Kovalovsky A, Reynders A, Khurana K. Intravascular papillary endothelial hyperplasia diagnosed by fine needle aspiration: Report of a case and cytology literature review. J Cytol. 2013;30: 42-5.

9. Choi YD, Kim Y, Kim SS, Kim JH, Nam JH, Choi C, Park CS. Intravascular papillary endothelial hyperplasia of the chest wall misdiagnosed as a malignancy on fine needle aspiration. Korean J Pathol. 2013;47:499-501.

10. Handa U, Khurana U, Singhal N, Punia RP, Mohan H. Cytologic diagnosis of intravascular papillary endothelial hyperplasia: A report of two cases and review of cytologic literature. Acta Cytol. 2012;56:199-203. 